\title{
Opportunity and Challenge of the Cultivation of Talents Under the Background of Artificial Intelligence
}

\author{
Xiren Li \\ Shanghai Academy of Shanghai university, Shanghai, China, 200032
}

\author{
Key Words: Artificial Intelligence; Cultivation of Talents; Opportunity; Challenge
}

\begin{abstract}
The rapid development of computer technology has been changing people's lifestyle and the mode of cultivation of talents, moreover the more and more mature AI technology has been gradually integrating into each aspect of our daily life. So, people have increasing demand for hightech talents of the AI field because of the higher and higher attention to the AI technology. So how to cultivate the high-tech talents of AI technology has drawn wide concern all over the society under the background of the development and transformation of AI technology. The rapid growth of AI technology has brought great transformation to various industries, furthermore the demand for talents and the cultivation of them have great impact on traditional industries in the technological change. As a result, the cultivation of talents under the background of the development of AI technology will meet both significant opportunities and challenges.
\end{abstract}

\section{Introduction}

In the twenty-first century, with the growth of the networking, Internet and Internet of Things all over the world, artificial intelligence and intelligence system have been integrating into various industries and highly valued by the administration in the age of big data, which leads to the fully attention to the cultivation of talents. The State Council of our country has clearly pointed out that we should cultivate compound-type talents with innovative personality and conduct the smart education project covering all the people in order to create advantages for the development of artificial intelligence. So, with the rapid growth of AI technology, the demand for the cultivation of talents and teacher's teaching ability have been higher and higher and deepening the reform of innovative education system of our country has been one of the crucial ways of improvement. AI technology has been widely used to various industries such as manufacture, agriculture, commerce and financial industry that may not only considerably improve the working efficiency but also change the working mode of people. In the time when AI technology has been increasingly important, the cultivation of talents of AI technology may embrace the great opportunities. However, facing with the circumstance of how to integrate the cultivation mode of high-tech talents of AI technology with the education of Internet technology, the cultivation of AI technology talents may still face the great challenges at the same time.

\section{Influence of AI to the Society}

AI technology has been widely used to industries such as industry, agriculture, commerce, financial industry and manufacture and it has substantially influenced on various aspects of human life like society, economy and culture. When mentioning the aspect of social employment, AI technology may totally replace human being of doing some kinds of brain work, which may lead to the elimination of some types of work or working modes of worker and finally cause the unemployment of parts of workers. As we can say, AI technology has already integrated into the daily life of human, for example intelligent robots can be seen everywhere, self-driving technology of automobiles has already been the new research direction and moreover AI technology has already been used in banks, restaurants, hospitals and financial services. With the wider and wider use of the AI technology, human's way of thinking and their traditional working concept have been changed at the same time. So, the more people will rely on the AI technology the more they will have higher and higher demands for talents of AI technology. 
While people are enjoying the great convenience that the AI technology brings, they may still feel the threat that the rapid growth of the AI technology brings and be afraid of being replaced one day. Moreover, some researchers of AI technology even point out that human may become the slavers of the AI technology or intelligent robots in the coming day. The strategic idea mentioned above may have impact on the development of AI technology and the cultivation of talents but in the advance of science and technology, how to cultivate high-tech talents of AI technology with sound quality and competence will be the major direction of the demands for talents. Therefore, continuously improving AI technology and adapting it into all walks of life will be the core measurement of enhancing productivity in the future.

\section{Strategy and Advice on the Cultivation of Talents under the Background of AI Technology}

\subsection{Expand the Way of Talent Cultivation}

The future employee will be deeply influenced by AI technology, so they have to equip with the ability of integrating the professional knowledge of technology with high performance computers. However, the current way of cultivating is still the model, in which teacher's presentation is the main part of the class and what students should do is just to listen to the teacher, especially in the low-level schools such as higher vocational colleges and secondary technical schools. The schools with the traditional way of cultivating can hardly meet the needs of society but we don't have to worry too much about the talent cultivation. We can embrace great opportunities of the cultivation of talents when we face with the challenge. Talent cultivation in the age of AI should be the driving force of both the Internet and Internet of Things with the way of education not only online but also offline. When we closely focus on the cutting-edge trends of research and development institutions of the profession itself, we still need to enhance and cultivate the ability of operation of students with the help of the advanced intelligent system. The image thinking of students will be highly improved through study of virtual visual image with VB language and furthermore the professional decisionmaking ability of students will be highly improved through the simulation of professional intelligent software. The interdisciplinary teaching of integrating the profession with the computer specialty will be the pioneer of the technical transformation of the cultivation of AI talents and provide huge numbers of talents with high-tech AI technology.

\subsection{Optimize the Training Process of Talents}

Nowadays scholars home and abroad have their own opinions on the cultivation of AI talents that mostly target at the talent demand of the profession itself and base on various national conditions. What we should do is to evaluate all these opinions comprehensively and learn experience from them. During the process of the education of colleges and universities, man-machine interaction should be the core-oriented theme that will cultivate the professional ability of operation by means of computer and computer technology. The traditional mode of teaching will be replaced by the new mode of student-teacher-profession-school through improving the understanding of intelligent machines. Furthermore, multi-disciplinary integration and the new teaching objectives and courses will help make the new teaching system. The new teaching mode integrating the practical curriculums with virtual reality technology based on the new teaching system that focuses more on the practice will be the major way of education in the coming future.

\subsection{Expand the Teaching Mode of Talent Cultivation}

The rapid growth of AI technology has deeply been influencing the whole world and making it better. So, the way of talent cultivation of AI technology should also be transformed from the traditional teaching mode to the new one that pays more attention to the cultivation of innovation ability, which will help improve the quality and master the advanced development trends. From the objective aspect, it is a long way for us to go for the cultivation of AI technology talents but we have no need to be panic and seek quick success and instant benefits. Since the reasons as differentiation of learning, age and distract, educators of our country still have to work harder in order to meet the higher demand. 
As we can say, in the process of continuous perfection and development of educational informatization in the future, the education platform of our country will accept more and more developers to study and perfect, which will lead to the great improvement of AI technology of our country and be the only way of the AI technology talent cultivation which must be passed. Furthermore, colleges and universities should attach more attention to the education of AI technology fundamentally while it should not be limited only to the classroom education of single school. The teaching mode of colleges and universities should adapt to the development of social requirement and connect closely to both the social educational institutions and social education, ending up to be the integrated education community to cultivate talents under the background of AI technology.

\section{Catch Opportunities and Face with Challenges of Talent Cultivation under the Background of AI Technology}

In the background of the economic globalization, AI technology will provide more complete scientific teaching mode. Furthermore, in the background of the fragmentation, diversification and big datafication of knowledge, only to adapt to the development trend of AI could let us enjoy the convenience that is brought by intelligent technology and fully deal with challenges brought by Internet technology. Meanwhile we have to become at ease with the disappearance of part of traditional industries and the unemployment of large numbers of people caused by the development of AI technology and science and technology. Therefore, we should focus more on the deep exploration of the innovation and aesthetic sense of human being and pressure of the cultivation of human's innovation to adapt to the needs of the AI development when facing with challenges.

AI technology has great impact on the traditional cultivation mode of talents. The traditional way that students may study knowledge just by memorizing mechanically will hardly meet the need of the desire for knowledge of talents in the contemporary age and the duck-stuffing type of teaching can definitely not conform to the great requirement of talents of the society with the rapid growth of science and technology. Only the talents with innovation and compound ability can adapt to the dynamic development trend of both the society and science and technology. High-tech talents in the new age can draw on the experience of the cutting-edge knowledge and fruit of science and technology while they promote the cultivation of AI talents based on the broadened vision of development. Only dealing with the challenges of the cultivation of AI talents calmly can we finally find the new mode of talent cultivation to seize opportunities and make great achievements.

\section{Conclusion}

As all mentioned above talent cultivation under the background of AI technology has been facing with unprecedented challenges. Talents with high quality will promote the rapid development of AI technology while the great improvement of AI may need more innovative talents. Therefore, the cultivation of AI talents will be the key point of national education. We need to realize the gap of ourselves to face with the current situation of the need of innovative talents all over the world and then conquer the difficulty on the basis of setting clear goal and direction, financial we can make our own effort for the improvement of AI.

\section{References}

[1] Tie-Jun Huang. Imitating the Brain with Neurocomputer A "New" Way Towards Artificial General Intelligence[J]. International Journal of Automation and Computing,2017,14(05):520-531.

[2] Mohamed A.Shahin. State-of-the-art review of some artificial intelligence applications in pile foundations[J]. Geoscience Frontiers,2016,7(01):33-44.

[3] Jonathan Michael Spector,Du Jing. Artificial Intelligence and the Future of Education:Big Promises-Bigger Challenges[J]. Geoscience Frontiers,2017,(04):257-265. 
[4] REN Fuji1, 2 and SUN Xiao1. Current Situation and Development of Intelligence Robots[J]. ZTE Communications,:2017,1 (01) : 05.

[5] Fei YAO,Lei JI,Chengyu ZHANG,Wu CHEN. Real-time virtual reference service based on applicable artificial intelligence technologies:The début of the robot Xiaotu at Tsinghua University Library[J].Chinese Journal of Library and Information Science,2011,4(02):12-26.

[6] R.Viswanathan,Pijush Samui. Determination of rock depth using artificial intelligence techniques[J]. Geoscience Frontiers, 2016,7(01):61-66. 